\title{
Forensic Notion of the Trauma-Related Dissociation
}

\author{
Vito Zepinic \\ PsychClinic P/L, London, UK \\ Email: vito@psychclinic.net
}

How to cite this paper: Zepinic, V. (2021). Forensic Notion of the Trauma-Related Dissociation. Beijing Law Review, 12, 948972

https://doi.org/10.4236/blr.2021.123049

Received: September 1, 2021

Accepted: September 23, 2021

Published: September 26, 2021

Copyright (c) 2021 by author(s) and Scientific Research Publishing Inc. This work is licensed under the Creative Commons Attribution International License (CC BY 4.0).

http://creativecommons.org/licenses/by/4.0/

\section{(c) (i) Open Access}

\begin{abstract}
Research and clinical experience reveals that severe traumatisation may cause development of Complex Trauma Syndrome (complex PTSD) with the trauma-related dissociation, which is often associated to the severe violence or crimes. Unlike other types of the dissociation or dissociative disorders, this subject matter is the most relevant to forensic psychiatry as severely traumatised individuals (with a history of dissociation) are often subjects of the court proceedings-dissociation has legal repercussions for relevance to the legal constructs of the accused's responsibility for the wrongdoing. Trauma victim's behaviour during dissociative flashbacks is quite unpremeditated and uncharacteristic, and does not appear to be an alternative motive as the most individuals experience amnesia for the episode, nor they are aware of the re-enacted trauma experiences. This article provides views and nature of the trauma-related dissociation and its forensic implications on trauma victim legal standing.
\end{abstract}

\section{Keywords}

Dissociation, Complex Trauma Syndrome, Traumatic Memories, Alterations, Amnesia

\section{Introduction}

Dissociation is defined as the disruption and/or discontinuity of normally integrated functions of the consciousness, memory, identity, emotion, perception, body representation, motor control, and behaviour which can potentially disrupt every area of psychological functions (American Psychiatric Association, 2013). In general, there are "positive" dissociative symptoms (i.e., flashbacks, intrusions into one's awareness, loss of self-continuity, fragmentation of identity and wholeness), and "negative" dissociative symptoms (i.e., amnesia) which result in 
an inability to access information or to control normal mental functions.

It is common that dissociation is influenced by the proximity or the aftermaths of trauma experience (i.e., Complex Trauma Syndrome). The DSM-5 placed dissociative disorders next to the stress-related disorders (but they are not part of these disorders) reflecting close relationship between two diagnostic classes. In fact, these relationships were recognised at the end of the $19^{\text {th }}$ century when a French psychologist P. Janet (1859-1947) was first to conceptualise dissociation as one's inability to integrate the "vehement emotions" of the severe stress or exposure to traumatised event(s) which induced a hysterical reaction (Janet, 1907). According to Janet, dissociation provides a critical defence against overwhelming traumatic experience, including childhood maltreatment, war trauma, torture, and rape, from which no actual physical escape is possible.

When a person dissociate it means splitting of some part or component of the mental activity which is sudden and temporary disruption of some aspects of one's consciousness, identity, or behaviour (Zepinic, 2018). A clinical picture of dissociation shows that individual's memory function of consciousness is altered, personality identity is disrupted, and motor behaviour is disturbed. The alterations of the normality integrated functions of identity, memory and consciousness may occur suddenly or on gradual onset, and could be transient or chronic in duration. Many clinicians are of opinion that dissociative phenomena are traumatically induced and exist on a continuum, and evolves over time into a maladaptive process which exceeds in inappropriate context (Zepinic, 2018).

As an aftermath of the severe trauma, the memories of traumatic experience cannot fully be integrated into one's personal awareness, and indeed they are split off (dissociated) from the conscious awareness and one's control. Thus, the comprehensive formulation of the effects of trauma upon the mind is based on a notion that failure to integrate traumatic memories as a narrative memory, due to extreme emotional arousal, results in development of Complex Trauma Syndrome (or complex PTSD) (Zepinic, 2018). In severe cases, the victims of trauma may develop "phobia of traumatic memories" which disrupts integration of the traumatic experience, and split traumatic memories off from the consciousness.

Such traumatic memories became integrated (or fixed) in one's unconsciousness and cannot be liquidated nor translated into a personal narrative. Thus, the unconscious memories continue intrude trauma victim as a terrifying perception, obsessional preoccupation, and somatic re-experiencing. Subsequently, the traumatised individual reacts to reminder(s) of the trauma experience with responses that had been relevant to the original trauma with no or with diminished adaptive values (Zepinic, 2018). Upon exposure to the reminder(s) of the trauma, the trauma victim experiences unconscious and out of control somatosensory representations because the traumatic memories are fixed to the trauma in the past (there-and-then) and stored in the individual's unconsciousness, or stayed fragmented. Janet (1925) proposed that the efforts to keep fragmented 
traumatic memories out of the one's conscious awareness erodes the psychological energy of the traumatised individuals. This interferes individual's capacity to engage in any proper focused and creative actions (here-and-now), and ability to learn from the trauma experience (van der Kolk et al., 1986) (Zepinic, 2019).

Severe trauma dissociates one's capacities and personality wholeness which are inconsistent with pre-trauma mental (and/or physical) state of coherence and continuity (Zepinic, 2019). This brings a notice that dissociation is an alteration of consciousness in which traumatised individual feels disconnected from the own self and/or from the environment. It does not mean that an individual is physically disconnected from the self or the environment, but trauma victim is consciously unaware of certain items or absence of relatedness with the self. This also includes sensory deprivation and inability to respond or to act accordingly. Dissociation may also represent coexistence of one's totally separated mental system or identities that should be ordinary integrated into person's consciousness, memory, or identity—personality wholeness (Zepinic, 2019).

This confused state of mind, often called stimulus entrapment (Meares, 2012) (Zepinic, 2017), causes that the person's consciousness and awareness of the inner events are not in function with diminished control over the inner conflict drives. Severe trauma overwhelms the ordinary human adaptation and resistance, as it usually involves the threat to life or bodily integrity, confronts trauma victim with the extremities of terror, and evokes the response of catastrophe (Zepinic, 2018) (Zepinic, 2017) (Putnam, 1989). The person's unconscious response to the "existing danger" is, in fact, one's underlaying condition of experiencing a real danger-abnormality of the mental functioning. This substantially impairs one's ability for rational judgment, understanding of his/her actions, and self-control (Bourget et al., 2017).

Numerous studies revealed close association between dissociation (i.e., amnesia, flashbacks) and crimes characterised by one's lack of planning, automatism, unawareness, heightened emotional states, lack of emotional ties to the victim of violence, and alcohol and/or drugs abuse. The accused's psychic disequilibrium is characterised by association between person's wrongdoing and dissociative flashbacks, amnesia of some aspects of the trauma (i.e., hidden traumatic memories), emotional numbing, and uncontrolled inner conflict drives, or the accused's experience of persistent or recurrent clinical features (i.e., depersonalisation and/or derealisation). Alongside with these features, the psychic disequilibrium of the PTSD patients with dissociation has higher rates of suicidal ideation, suicide attempts, and self-mutilation behaviour than those who suffer PTSD without dissociation (Zepinic, 2019).

\section{Dissociation and Complex Trauma Syndrome}

Since Janet's experimental approach toward the phenomena of dissociation (Janet, 1907), in 1930's the psychiatry was sweeping aside dissociative model of 
psychopathology and interpretation of dissociation. The main reason for that was conflict concerning recognition of the mechanisms of hysteria between the dissociative and psychoanalytic models. In his review of The Major Symptoms of Hysteria, Janet stated his happiness that the results and his findings about dissociation (hysteria) have been confirmed by Freud and Breuer (Freud \& Breuer, 1893). On the other hand, the psychoanalysts were protesting that, in dissociative model, there was not finding of dual or multiple personality by the clinicians in practice and that these altered personalities were artifacts hypnotically induced; and that deliberately induced symptoms by hypnosis are not a clinical picture of the hysteria.

A return in interest for dissociation occurred following clinical interest in psychopathology of multiple personality disorder and posttraumatic stress syndrome. Since the PTSD introduced as an independent disorder, there have been considerable debates about dissociation as a central feature of posttraumatic pathology, and in particular within the Complex Trauma Syndrome (complex PTSD). Public awareness of the chronic child abuse, which often causes complex and chronic stress disorder, and clinical picture of the Complex Trauma Syndrome with a chronic dissociative pathology significantly contributed in the studying dissociation. Furthermore, dissociation, as the major causes of such psychopathology, provides a greater acceptance of the traumatically induced dissociative disorders. Thus, clinical experience of the hidden-observer phenomenon has stimulated a return to laboratory investigation of the dissociation (Zepinic, 2018) (Putnam, 1989).

\subsection{Complex Trauma Syndrome}

Some clinicians argue that Complex Trauma Syndrome (complex PTSD) should be classified as a dissociative disorder; others suggest that many individuals who developed PTSD do not experience dissociative symptoms. The DSM-5 (American Psychiatric Association, 2013) suggests there might be distinct subgroups of PTSD, namely with and without clinically significant dissociation. In the light of evident closeness between PTSD and dissociative disorders, the diagnostic manual placed next to each other of these two related disorders. Thus, most definitions of dissociation primarily concern person's consciousness, a sense of identity, and alterations of the self's wholeness which represent a pathological (dissociative) process. Vast majority of the clinicians are agreed that disruption of normal integrative functions has been the essential issue in definition of dissociation.

In essence, two main principles can be used to characterise the most forms of dissociation and its psychopathology. The first is that the individual experiencing dissociation suffers an alteration in the sense of the identity. In clinical practice is evident that these disturbances may occur in different variety of formsi.e., partial or complete amnesia for self-referential information (age, name) in form of psychogenic amnesia or fugue states, or the existence of series of differ- 
ent identities which are independent from each other (often even confronting to each other). The second principle of pathological dissociation is a disturbance(s) in the individual's memory for the events which occur during the period of dissociation. These two principles are recognised by the DSM-5 which defines dissociative disorders characterised by a disruption of and/or discontinuity in the normal integration of the consciousness, memory, identity, emotion, perception, body representation, motor control, and behaviour (American Psychiatric Association, 2013).

Working with the severely traumatised individuals over more than two decades, (Zepinic, 2019) found the following clinical features of dissociation in Complex Trauma Syndrome (complex PTSD): 1) amnesia (recurrent memory problems often described by the patient as "losing time"-this feature can vary from several minutes to several months); 2) depersonalisation (a sense of detachment or disconnection from trauma victim's self-the person feels that the own self is a stranger, or feeling like a part of self not belong to a person); 3) derealisation (a sense of disconnection from familiar people or one's surroundings, or that familiar people (including family members) and surroundings are unreal or foreign); 4) identity confusion (a person struggles about sense of self/identity, which may involve uncertainty, or conflict in particular regarding sexual identity among sexually abused individuals); and 5) identity alteration (a sense of acting like a different person some of the time-identity alteration includes using different names, discovering that known items are not recognised).

Trauma syndrome compromises an altered conception of the self in relation to the intra- and outer world based on being fixed on the trauma experience and having an atypical dream life, with chronic irritability, startle reactions, and explosive aggressive reactions, or no reactions at all (Zepinic, 2016). This condition is a result of the fact that one's traumatised self is dedicated to the specific acts of ensuring security of the organism, and trying to protect itself from painful recollection of the trauma. Intrusive thoughts about trauma prevent trauma victim to think positively or to make an analytic answer about relations between a trigger (reminder) and intrusive thoughts (Zepinic, 2019), (Herman, 1992), (Wang et al., 2009).

The DSM-5 has recognised that dissociation is often an aftermath of trauma, and many of the symptoms, including embarrassment and confusion about the symptoms or a desire to hide them, are influenced by the proximity of experienced traumatic event(s) (American Psychiatric Association, 2013). Furthermore, while diagnosing posttraumatic stress disorder, the DSM-5 requires to specify whether disorder occurs with dissociative symptoms, either in form of derealisation and/or depersonalisation. Some authors (van der Kolk et al., 1986) (Zepinic, 2019) (Bourget et al., 2017) (Holmes et al., 2005) consider that flashbacks to be stress-related dissociative symptoms because such re-experienced symptoms involve features of patient's detachment (i.e., a sense of separation from reality) that are essentially dissociative. 
Dissociation as potentially main features of complex trauma syndrome should be considered within the time-frame of its occurrences: peritraumatic dissociation occurs during and/or immediately following severe traumata (stressor), acute posttraumatic dissociation occurs during first week or two after the event(s), and chronic dissociation may continue for years after the stressor (Zepinic, 2021b). Thus, dissociative phenomena may occur in varied times after the event (stressor) through different causal pathways and could be characterised by different pathological functions of the psyche, somatic, or behavioural malfunctions. Also, it could be one or more causes for dissociation that emerges at a particular time and pathway after the traumatic event(s).

Most forms of dissociation, including depersonalisation, derealisation, gaps in awareness, or amnesia, serve the function of alterations or distancing an individual from surrounding, and occurs as a response to extreme psychological arousal. After the traumata (event) is over, dissociative experiences serve to protect the trauma victim by providing emotional distance from the distress triggered by reminder of the event(s). Depersonalisation and derealisation occur as a direct emotional distance by distorting perceptions of the traumatised self from the traumatic event (i.e., "what was happening wasn't really happened to me"). Gaps in awareness and amnesia are direct ways to exclude trauma experience from one's awareness. However, the aftermaths of the trauma experience (traumatic memories) are often unconscious of which the trauma victim is totally unaware and they are run by the inner conflict drives (Zepinic, 2016) (Herman, 1992).

Since for the first time being considered as a central feature of the stress disorder, the vast majority of the clinicians are agreed that dissociation is, more or less, an integral part of the diagnosis of PTSD, in particular in case of Complex Trauma Syndrome (complex PTSD). Many clinicians (van der Kolk et al., 1986) (Zepinic, 2019) (Herman, 1992) (Spiegel \& Cardena, 1991) (Waelde et al., 2005) argue that dissociation is central to both the development and the maintenance of PTSD and that dissociative symptoms are equally important to both the concept and the diagnosis of the PTSD. However, some study (Harvey \& Bryant, 2002) had found that, although dissociation is correlated with trauma syndrome, it is not necessarily inherent in PTSD due to the substantial individual differences in dissociation among those who were victims of the traumatic event(s).

Studies have attempted to resolve discrepant findings and opinions among clinicians about dissociation role in the PTSD mostly reviewing relative contribution between peritraumatic and persistent dissociation as a factor for further experience of the stress event(s). Some studies (Briere et al., 2005) of dissociation found that the persistent dissociation was a stronger predictor of chronic PTSD than peritraumatic dissociation. A study of the civilian trauma survivors (Van der Velden et al., 2006) suggests that persistent or ongoing dissociation is strongly related to severe stress disorder. Trauma represents the ultimate experience of helplessness: loss of control over one's own body, mind, and emo- 
tions. From our clinical practice, there is evidence that dissociation occurs as a defence during traumatic experience, constituting the trauma victim's attempt to maintain mental control at the moment when physical control has been lost (Zepinic, 2019) (Zepinic, 2021b).

On the other hand, study (Waelde et al., 2015) among trauma-exposed Vietnam veterans found that elevated dissociative symptoms characterised a specific subgroup of dissociation. These trauma victims shown significantly higher posttraumatic symptoms than the other traumatic or non-trauma related groups. According to the authors, $85 \%$ of Vietnam veterans had current PTSD but only $18 \%$ of other stress-related victims had current PTSD. Based on this study, it is logical to conclude that the severe or repeated trauma experience is a presumption for developing Complex Trauma Syndrome (complex PTSD) characterised by an existence of the persistent dissociation.

For last two decades, many clinicians (Zepinic, 2019) (Cloitre et al., 2019) (Courtois \& Ford, 2009) (Lechner-Meichsner \& Steil, 2021) suggest distinction between complex PTSD from simple PTSD considering that dissociation are usually expected to occur from the repeated interpersonal traumatic events which cause Complex Trauma Syndrome (complex PTSD). Complex PTSD is defined as a new category in the ICD-11 (World Health Organisation, 2018) being distinct from its PTSD-sibling, and other stress-related disorders. Studies (Zepinic, 2019) (Zepinic, 2021a) (Cloitre et al., 2019) (Zepinic, 2021c) found that an increased depression, evidence of the suicidal behaviours, dissociative symptoms, as well as some unspecific psychopathological symptoms (i.e., sleep problems, eating disorder, other psychological problems) also characterised Complex Trauma Syndrome (complex PTSD). In general, the Complex Trauma Syndrome (Zepinic, 2021a) (Zepinic, 2021b) highlights the trauma impact of prolonged and/or repetitive interpersonal stress upon the trauma victim's self independently of PTSD standard triad cluster symptoms (hyperarousal, re-experience, and avoidance) (Zepinic, 2021b).

According to the ICD-11, the complex PTSD retains the core triad cluster: 1) avoidance of internal and external trauma reminders related to the event(s);2) re-experiencing traumatic event in the form of the flashbacks, nightmares, or vivid intrusive memories typically accompanied by strong emotions like fear or horror; and 3) persistent-heightened sense of current threat, indicated by the hypervigilance or increased startle response (Zepinic, 2019). However, in defining complex PTSD the ICD-11 added disturbances in self-regulation (DSO) clusters which proposed that an individual can only be diagnosed with simple or complex PTSD, but not both.

Alongside with the core symptoms (hyperarousal, avoidance, and re-experiencing) of the simple PTSD, the ICD-11 defines complex PTSD with suffered disturbances in self-regulation: 1) problems in affect regulations (i.e., heightened or lowered emotional reactivity; feelings of neediness, dejection, hopelessness, dissociative experiences, or emotional numbing); 2) altered or negative self-concept 
(i.e., feelings like failure or worthlessness; incompetence, shame, inadequacy, loss of self-consciousness); and 3) impaired interpersonal relationships (i.e., difficulties in establishing and/or sustaining interpersonal connections, or avoidance of relationships, isolation, dejection or rejection) (Zepinic, 2021b).

Affect regulation is a multidimensional construct involving: 1) awareness, understanding, and acceptance of the emotions; 2) ability to control impulsive and self-harm behaviours when experiencing negative emotions; 3) flexible use of situationally proper strategies to modulate and control the intensity and duration of emotional responses; and 4) volition to experience negative emotions in the pursuit of meaningful activities (Zepinic, 2019). As an aftermath of the severe trauma, the trauma victims may develop difficulties in the self-regulation (i.e., self-esteem maintenance, affect tolerance, loss of sense of the self-continuity or a sense of personal agency). As such, the individual may dissociate and alter the own personality into the "third person's personality".

The ICD-11 division of PTSD into two qualitatively different disorders has been supported in numerous studies and clinical observations (Brewin, Bryant, Cloitre, Courtois, Ford, Herman, Horowitz, Maercker, van der Kolk, Wilson, Zepinic) even long before the WHO released its classification of diseases and related problems. Studies have consistently demonstrated that Complex Trauma Syndrome (complex PTSD) is associated with more comorbidity, significantly worse functioning, alterations in personality, dissociation, and worse quality of life compared with those individuals who suffered simple PTSD (Zepinic, 2019) (Herman, 1992). Also, studies (Cloitre et al., 2019) (Brewin et al., 2017) (Hyland et al., 2017) revealed that the Complex Trauma Syndrome (complex PTSD) is a more severe disorder than simple PTSD in clinically meaningful ways.

The ICD-11 (World Health Organisation, 2018) emphasised that the complex PTSD (CPTSD) is particularly associated with emotional disorders (i.e., depression, anxiety, dissociation, sleep disturbances, somatisation, aggression, dysthy$\mathrm{mia}$ ) and predominantly related to the disturbances in self-organisation (DSO). The DSO domain in the CPTSD is found to have overlapping symptoms with prominent symptoms of emotional disorders, especially depressive symptoms such as feeling worthless, interpersonal withdrawal, emotional avoidance, feeling cut-off from others, and difficulty in staying close to the others (Zepinic, 2019) (Zepinic, 2021a) (Gilbar, 2019) (Hyland et al., 2019).

Furthermore, the ICD-11 found that CPTSD is associated with psychotic symptoms such as mind-reading, experiencing special messages sent through the TV or radio, being under the control of some extraordinary power, a feeling of having extra-special powers, feeling that people were following or spying on trauma victim, and auditory and visual hallucinations (Frost et al., 2019). Exploring characteristics which are associated with and central to PTSD, as compared to the CPTSD, gained knowledge which may 1) uncover symptoms that account difference in the comorbidity between PTSD and CPTSD, 2) be useful in identifying different therapeutic approach to these two disorders, and 3) im- 
prove differential diagnosis between the PTSD and the Complex Trauma Syndrome (complex PTSD) (Zepinic, 2021a, 2021b).

There are numerous studies and clinical observations which revealed that dissociative experiences occur in an individual's reaction to severe trauma event(s), or reminders of them. Such dissociative reactions can manifest as a daily disruption in perception of time, physical sensations, memory, sense of self and personal identity, and/or sense of reality. Also, trauma-related dissociative reactions may lead to development of dissociative disorders (dissociative identity disorder, dissociative amnesia, depersonalisation and/or derealisation disorder) which are characterised by a disruption of and/or discontinuity in the normal integration of memory, consciousness, identity, emotion, perception, body representation, motor control, and behaviour (Zepinic, 2021b). In essence, dissociative symptoms can potentially disrupt every area of individual's psychological functioning.

The DSM-5 (American Psychiatric Association, 2013) defines that the dissociative symptoms in PTSD are experienced as: (a) the unbidden intrusions into individual's awareness and behaviour, with accompanying losses of continuity in subjective experience (i.e., "positive" dissociative symptoms such as one's fragmentation of identity, depersonalisation, and derealisation) and/or (b) inability to assess information or to control mental functions that normally are readily amenable to assess or control (i.e., "negative" dissociative symptoms such as amnesia). In essence, it is important to differentiate clinically significant dissociation from the normal dissociation. Some of clinical presentations (i.e., identity confusion, derealisation, depersonalisation, amnesia, fugue) are relatively uncommon in nonclinical dissociation under normal circumstances (Zepinic, 2018).

Trauma-driven dissociative symptoms usually solidify into a trait-like notion (i.e., identity confusion, emotional constrictions, memory disturbances, depersonalisation, derealisation) of the Complex Trauma Syndrome (complex PTSD). These dissociative tendencies are related to the proximity and severity of the stressor(s) and positively associated with the intensity of Complex Trauma Syndrome (complex PTSD) symptoms. Some individuals who experienced severe repeated and/or prolonged traumata suffer intense dissociative symptoms to the reminders of the previous traumatic experiences, new traumatic stressors, or even minor life stressor(s). Such psychological reactivity to the threat of exposure to cues reminiscent of previous experience are worsened among trauma victims when they face with the prospect of more stress. Numerous studies among the combat veterans reported severe symptom-exacerbation when they were exposed to a stressor which reminds them of the original traumata.

Fragmented traumatic memories (usually totally unconscious) may occur vividly and intensely in the daily life of the trauma victim. DSM-5 (American Psychiatric Association, 2013) describes the phenomena of fragmented memories via intrusive symptoms of the PTSD and other stress-related disorders, in- 
cluding dissociative disorders. Within the PTSD (in particular complex PTSD) some of intrusions occur dissociative in forms of distressing recollections, perceptions, and images of traumatic event; as well as to re-experiencing of the traumatic event in dreams and daydreams; flashbacks, nightmares or reliving trauma experiences; and physiological and psychological reactivity upon exposure to reminder of the traumatic event (internal or external cues which symbolise traumatic event (Zepinic, 2019) (Herman, 1992). From the perspective of dissociation, intrusive symptoms are vivid sensations, emotions, and memory fragments of the traumatic experience that break into consciousness (Van der Hart et al., 2006), or dissociation is a division among systems of ideas and functions that constitute the personality (Janet, 1907).

\subsection{Conception of Dissociation}

In essence, clinicians are agreed that 1) dissociation are often normal features of the person, 2) it occurs in mental illnesses (i.e., schizophrenia, personality disorders, substance-related and addictive disorders, PTSD). The common between two large groups of dissociation is sudden, temporary disruption of some aspects of consciousness, emotions, identity, or motor behaviour. It is out of scope of this article to elaborate appearance of normal dissociated state or dissociation in other mental health disorders (i.e., schizophrenic patient laughs heartily while discussing own delusions that he/she was cut into a million pieces). The attention in this article is given to the trauma-related dissociations which are, unlike the other dissociation, mostly present in the courtroom. The individuals who sustained Complex Trauma Syndrome (complex PTSD) with the trauma-related dissociation may experience psychogenic amnesia, alteration of the memory functions, alteration in personal identity and a sense of the self, and disturbances in both the emotions and motor behaviour (Zepinic, 2019).

Numerous studies (Myers, Ferenczi, Kardiner, Horowitz, McDougal, van der Kolk, Herman, Wilson, Zepinic) stated dissociation as a division of the personality in traumatised individuals, in particular those who had experienced severe traumatisation. Clinicians noted that the dissociative mental actions (i.e., perceptions, emotions, images, flashbacks) do not exist in a vacuum but they are always part of the trauma victim's personality, either as the conscious or unconscious constructs (Zepinic, 2019) (Herman, 1992). However, in vast majority of such condition, dissociative parts of personality cannot be adequately described by the individual as an idea or group of ideas (wholeness), but rather as the individual's self-conscious purposive thinking of a part or disconnected parts of the personality (Zepinic, 2019).

Dissociation could be conceptualised as a lack of integration of one's mental functions when an exposure to traumatic event(s) induced out of control reactions (inner conflicts). According to the clinicians (Putnam, 1989) (Bourget et al., 2017) (Zepinic, 2019) (Holmes et al., 2005) (Waelde et al., 2005) there are at least three conceptions of dissociation: 1) it is fascinating phenomenon involving 
the loss of or change in identity, or memory, or feeling of detachment due to the experience of traumatic event(s);2) dissociation seems to arise in response to the severe trauma; and 3) dissociation as a phenomenon teaches us about information processing of trauma in the brain.

Some clinicians in the trauma field believe that neither DSM-5 nor ICD-11 fully define trauma-related disorders (PTSD and others) and their dissociation associated with. Dissociation can be understood phenomenologically as a splitting of the patient's self-awareness such that the individual experiences perceptions, emotions, thoughts, motives, and action as organised by the self which is either transiently absent (i.e., the fugue states, loss of memory), alien (i.e., depersonalisation), altered (i.e., derealisation), or fundamentally altered as seem to be quite distinct other selves (Zepinic, 2018). Some clinicians (Zepinic, 2019) (Holmes et al., 2005) proposed that dissociation includes two distinct categories of dissociative phenomena: detachment and compartmenalisation.

Detachment is defined as an altered of consciousness characterised by a sense of separation from aspects of everyday experience (Holmes et al., 2005). Due to the detachment, there is also absence of emotional experiences during the altered states of here-and-now circumstances. Detachment is often an aftermath of trauma causing depersonalisation (an altered state of consciousness making discontinuity between one's mental state and physical body), or derealisation (an experience of the outer world as strange, unreal, or even dangerous).

Compartmentalisation is defined as a phenomenon that meats four criteria: 1) a deficit in the ability to maintain deliberate control of processes or actions which would normally be amenable to such control; 2) the deficit cannot overcome by an act or will; 3) the deficit is reversible; and 4) it can be shown that the apparently disrupted functions are operating normally and continue to influence one's cognition, emotion, and behaviour (Holmes et al., 2005). Clinicians are agreed that two distinct categories of dissociation are linked to overwhelming trauma as many trauma victims during such experience did not show effective coping strategies nor developed survival skills making trauma is like one never ending process (Zepinic, 2017). The symptoms reflecting such condition include dissociative flashbacks, psychogenic amnesia for some aspects of the trauma, and severe emotional numbing which often leads to high rates of suicidal ideation or attempt, and self-injurious behaviour.

The complexity of trauma-related dissociation constitutes specific organising principles in treating dissociative mental actions aiming to integrate the basic personality principles from 1) stabilisation and symptoms reduction through 2) integration of dissociative parts of personality, and then towards 3) personality integration to a degree in which the patient has success in major areas of a normal life free of fears from the traumatic past. From the forensic point of view, the most meaningful types of dissociation in the courtroom are dissociative amnesia and dissociative identity.

Dissociative amnesia is characterised by an inability to recall autobiographical 
information (American Psychiatric Association, 2013). The DSM-5 recognised existence of three types of dissociative amnesia: localised (i.e., inability to recall an event or period of time); selective (i.e., inability to recall a specific aspect of an event); and generalised (i.e., alteration in one's identity and life history). From the forensic point of view, it is worthy to note distinction between inability to recall autobiographical information in dissociative amnesia and normal forgetting processes. In clinical practice, some patients may report awareness of "lost time" or they have a gap in their memory (i.e., in severe psychosis (i.e., schizophrenia), or substance-related and addictive disorders); however, in case of the dissociative amnesia the patients are usually unaware of their amnesias. For them, awareness of amnesia occurs only when personal identity is lost or when circumstances make these individuals aware that autobiographical information is missing (American Psychiatric Association, 2013).

Dissociative identity is characterised by the presence of two or more distinct personality states, or unrelatedness between mind and body which belongs to two different persons, or an experience of possessing some personality traits that belong to the "stranger". For the forensic point of view, it is necessary to make distinction when fragmentation of identity as an aftermath of religious or cultural beliefs (i.e., some specific beliefs about death and spirit).

Thus, the individuals may experience discontinuities in their identity during the religious experiences which are not dissociation. In trauma-related dissociative identity, the person experiences: 1) recurrent, inexplicable intrusions into their consciousness and sense of the self (i.e., intrusive thoughts, emotions, and actions); 2) alterations of a sense of the self (i.e., feelings like one's body or actions are not one's own); 3) odd changes of perception (i.e., feelings of detachment from one's own body); and 4) intermittent functional neurological symptoms (i.e., psychological blindness, mutism, or paralysis of the body parts) (Zepinic, 2019).

\section{Trauma-Related Dissociation in Courtroom}

When talking about trauma-related dissociation we should make distinction from dissociation of the dissociative disorders (i.e., dissociative identity disorder, depersonalisation disorder, derealisation disorder, other specified dissociative disorder, unspecified dissociative disorder) and dissociation in personality disorders, or other mental health disorders (i.e., schizophrenia, substance-related, addictive disorders). Despite close relationship between these clusters and that dissociation is a core feature of the dissociative disorders, in this article is written about the dissociation as a part of the Complex Trauma Syndrome (complex PTSD), and not as an independent diagnostic entity. The key features reflecting trauma-related dissociation are dissociative flashbacks, dissociative amnesia for some aspects of the trauma, and emotional numbing (Zepinic, 2021b).

Severe trauma (i.e., war combat, brutal or repeated rape, childhood abuse, battered women) affects all structures of the trauma victim's personality-one's 
image of the body, sense of self, and the one's values and ideals-and leads to a sense that coherence and continuity of the self are systematically broken down (Zepinic, 2019). Severe trauma overwhelms the ordinary human adaptation and resistance as it usually involves the threat to life or bodily integrity and confronts the trauma victim with the extremities of the helplessness, hopelessness, and terror, and evokes the response of catastrophe. The trauma-related dissociation is frequently so severe and associated with a high rate of mental health treatment and substantial burden compared with dissociation in other psychiatric disorders. This dissociation may also be an important predictor for treatment resistant condition, high rates of suicidal ideation, and high relapse rates in treating patient who suffers Complex Trauma Syndrome (complex PTSD) (Zepinic, 2019).

Those trauma victims who have sustained Complex Trauma Syndrome (complex PTSD) with dissociation often formed stronger conditioned fear responses to both traumatic past and de novo events (Zepinic, 2019). In contrast, deficiencies have been in their explicit or declarative memory (i.e., inability to report accurately trauma experience).

In court case (unreported) Prosecution v Anto Furundzija [1998] before the ICTY $^{1}$ in The Hague, the paramilitary solder tried for aiding and abetting the brutal and repeated rape of a woman during the civil war. The accused's defence suggested that the rape victim's memory is inaccurate because it had been adversely affected by her extreme traumatic experience (civil war) and that the accused she identified was not actually present during the rape. Forensic experts on both sides were brought in to provide medico-legal testimony about the rape victim's trauma memory parameters and long-term effects of the traumatic experience on her personality.

The forensic reports highlighted many aspects of Complex Trauma Syndrome (complex PTSD) with dissociative amnesia. The rape victim has more memory fallibility and accuracy of the current and pre-trauma ordinary issues than about particular details of the traumatic event.

Statistically, about two-third of the mental health disorders present in the courtroom belong to the cases which consider the PTSD and other stress-related disorders. Numerous studies revealed that severe trauma may cause substantial personality changes: alterations of ability to modulate emotions, alterations of identity and sense of the self, alterations of ongoing consciousness and memory, alterations in perception of the perpetrator, alterations in relations with others and intimacy, alterations in one's physical and medical status, and alterations in system of meaning (Zepinic, 2019). For example, combat veterans diagnosed with the war-related PTSD are two to three times more likely to be violent towards a female partner than are veterans without PTSD.

Public awareness of the serious features of the severely traumatised individuals is usually highlighted because of trauma victim's appearance in the court${ }^{1}$ The International War Crimes Tribunal for Former Yugoslavia. 
room due to committed some violence or some type of breaking law. However, it is rare that the trauma victims appeared as the plaintiff against perpetrator in the criminal case-it is mostly event that trauma victims appear as a witness for the prosecutor. There is no doubt that the mental illness, even severe such as the Complex Trauma Syndrome (complex PTSD), is still a cause of stigma for those who have suffered, as well as society at large (Zepinic, 2017). In law, some judges even stigmatise the use of psychiatric damages as it is "misleading and inaccurate", on the proviso it is understood to refer to the psychiatric illness which results from emotional stress, and not the emotional stress itself ${ }^{2}$.

For example, in Relly $^{3}$ case the court found that the fear, chest pain, panic and discomfort, vomiting, sleeplessness, nightmares, and claustrophobia, which an elderly couple (plaintiffs) suffered over a two-month period due to negligently maintained hospital lift, was a "normal emotion in the face of a most unpleasant experience, for which it was the sound policy of the law not to provide compensation" (sic). Whereas in principle even minor physical injury will be entitled to recovery, the negligent or purposeful infliction (i.e., POW, child abuse, severe or brutal rape, battered women syndrome, etc.) of purely emotional harm such as complex trauma experience, which is recognisable and diagnosable in medicine, is not considered under the law of tort (Zepinic, 2015a).

The English law of tort limits its engagement with emotional distress (even accompanied by clinical evidence of dissociation) being preoccupied with a physical injury and social disorder. The law needs to prove damages which must be visible or demonstrable with the physical manifestations as prerequisite of liability. The "injury of feelings" is identified in terms of insult and affront rather than as emotional distress and suffering, and the mental illnesses are not conceived in biological or psychological terms. Even more, in some court cases, severe emotional distress was seen as "parasitic" to the physical injury under umbrella of the "pain and suffering". The mental pain is seen as legally unquantifiable and unfocused in the law's conception of the remediable emotional harm (Herman, 1992) (Spiegel \& Cardena, 1991) (Mullany \& Handford, 1993). Indeed, it is necessary to be conscious that this area of "pain and suffering" due to psychiatric condition is still developing with evident gap between the medicine and the law.

From the medical point of view, medical condition such as the Complex Trauma Syndrome (complex PTSD) and other stress-related disorders should be recognised by the law as those who suffered are victims of the crime against humanity (i.e., child abuse, terrorist act, severe rape, domestic violence, etc.). The trauma victims, as the plaintiffs, suffered a recognisable illness which the law does not, or very rare, recognise for recovery. When assessing the test of foreseeability in a psychiatric damage as a result of an injury or fear of injury to another person (Criterion $A$ of the DSM-5), it is first necessary to consider whether the psychiatric damage is reasonably foreseeable, and whether the defendant ${ }^{2}$ See: Alcock v Chief Constable of South Yorkshire Police [1992] 1 AC 310 (per Parker LJ at [351]). ${ }^{3}$ Relly \& Relly v Merseyside Regional Health Authority [1995] 6 Medical LR, 249. 
(perpetrator) assumes that the plaintiff is a person of "customary phlegm" and has "a normal standard of susceptibility" (Zepinic, 2015a).

The condition of stress-related disorders is an aftermath from deliberate wrongdoing by an individual or groups aimed at the trauma victim (the plaintiff). It is common under the law that the wrongdoing is an act calculated to cause physical harm and it is actionable if physical harm result. However, it is common sense that an intentional act against person (i.e., sexual and/or physical assault, rape, torture) is causing psychological shock which creates the shock-related injuries-psychiatric damages. The aftermath of an intentional wrongdoing should run parallel with the growth of liability for psychiatric damage.

Some courts recognised liability for the intentional infliction of the psychological shock and psychiatric damages but mostly in the legal defence when trauma victim has been accused of wrongdoing. This is in particular when battered woman is accused of murder or manslaughter on her abuser. While reading some court files of accused battered women, we can find that woman had repeatedly been beaten, threatened, and humiliated by her abuser before she committed a murder or grievous bodily harm upon him. However, for some judges it was irrelevant and therefore inadmissible to the question of whether the accused (battered woman) had acted voluntarily (instinctively) or intentionally and without lawful excuse (Zepinic, 2017, 2021a).

Thus, in the courtroom the trauma victim (with suffered trauma-related disorder) must use psychiatric damage as self-defence-the defence to demonstrate that those who have lived under repeated domestic violence had sustained Complex Trauma Syndrome (complex PTSD or other stress-related disorder). Despite suffering psychiatric illness, the battered woman trauma victim shall demonstrate absence of mens rea ${ }^{4}$ when committing wrongdoing act-even being repeatedly subject of the intentional wrongdoing by the plaintiff (abuser), the battered woman must submit that her action (murder or grievous bodily harm) was not intentional. The point is that battered woman who killed her batterer did so through her fear whereas provocation to do so requires, in the courts, to provide the evidence of loss of the self-control and anger (Loveless, 2012).

In the end, an abnormality of the accused's mind (which not be a brain disease) must shaw substantial impairment in mental responsibility for the act (i.e., reduced powers of control, judgment, or reasoning to a condition that would be considered by the ordinary person-per $R$ v Byrne [1960] 2 QB 396). The court recognised that the battered woman had suffered psychological syndrome as a result of prolonged and extreme physical and emotional abuse by her partner. Taking this into account, it is reasonable that the courts should not acquit the accused based on insanity defence (due to serious psychiatric disorder) but the wrongdoing act may be seen as rational, necessary, and reasonable, even avoidable to the criminal act in particular if, in case of the battered women syndrome, ${ }^{4}$ Actus not facit reum nisi mens sit rea (an act does not make a person guilty of a crime unless his/her mind also is guilty). 
the violence by the batterer was addressed to the children as well (Zepinic, 2017) (Zepinic, 2021a).

One of leading law cases of the battered women syndrome was $R v$ Falconer heard before the Full court of the High Court of Australia and $R V$ Ahluwalia heard before the House of Lords in UK ${ }^{5}$. In Falconer case, a woman was accused of killing her husband who discovered from her adult married daughters that, in their childhood, the father had dealt with them sexually. Just before the shooting, the deceased taunted Mrs Falconer in a way which suggested to her that he had had some sexual dealings with their youngest girl. The case revealed that not only physical abuse (battering) was in the marriage but battered woman suffered psychological stress due to repeated humiliation, betrayal, bullying, etc., which caused significant impact upon the wife's personality.

In Falconer case, the defence relied on the evidence by two psychiatrists who were of opinion that the accused's acted under dissociative state of mind. One of forensic psychiatrist stated: "I think she could have panicked and that could have been the mechanism which realised the full-blown dissociative state. Where part of her personality would be sort of segmented and not functioning as a whole and she became disrupted in her behaviour, without awareness of what she is doing". It was evident that the accused developed trauma-related dissociative symptoms due to persistent and long-lasting battering which leads to the condition of her dissociative amnesia. Dissociative amnesia is a stress-related disorder characterised by an inability to recall important personal experience and events that is inconsistent with ordinary forgetting. It causes significant distress and/or individual's impairment and appears in the absence of brain damage, and it is not related to substance abuse or related to other health problems.

In case State $v$ Janes $^{6}$, the US court permitted introduction of the battered women syndrome as an insanity defence plea. The trial judge delivered:

"If defendant is charged with an offence involving the use of force against and the defendant enters a plea to the charge of not guilty by reason of insanity, the person may introduce expert testimony of the 'battered women syndrome' and expert testimony that the defendant suffered from that syndrome as evidence to establish the requisite impairment of the defendant's reason, at the time of the commission of the offence, that is necessary for finding that the defendant is not guilty by reason of insanity... Many courts have found that battered women syndrome is not a mental disease, defect, or illness. Rather, the syndrome is considered a form of posttraumatic stress disorder, which is 'an anxiety-related disorder' occurring in response to traumatic event outside the normal range of human experiences".

Persistent dissociation which occurs after a traumatic experience and continues over time, contributes to the maintenance of the trauma syndrome (Herman, 1992) (Zepinic, 2021a) (Zepinic, 2019) (Werner \& Griffin, 2012). Some indi- 
viduals have trauma-related dissociative symptoms (i.e., depersonalisation, derealisation) for moths or years after the trauma event(s), which lead support to a dissociative subtype of the PTSD defined in the DSM-5. Using epidemiological data from 16 countries, the World Mental Health Survey (Stein et al., 2013) reported that $14.4 \%$ of the respondents diagnosed with the PTSD met criteria for dissociative subtype-the symptoms revealed severe impairment in trauma victim's day-to-day functioning, suicidality, and increase violent behaviour.

From the law point of view, those individuals who suffered dissociative type of PTSD are often subject of the criminal proceedings due to their aggressiveness and committed crimes (i.e., murder, violence, abuse) in stage of the dissociated mind due to the flashbacks. In such court cases, the psychiatrist or clinical psychologist may be called to provide clinical opinion about the accused's mental state at the time of a delict. The clinician's role is to establish a clinical picture suggestive of dissociation and clarify opinion about the offender's mental health during and after the delict. The request for the medico-legal report could be either by the prosecutor or the defendant in order to take into account, or to rule out, the impact of dissociative symptoms upon the accuser's mind (mens rea).

Forensic consultation, evaluation, and testimony are qualitatively distinct from evaluation for treatment purposes and often require many complex determinations (Simon \& Gold, 2004). The forensic expert should thoroughly be informed about the relevant legal case issues, regulation, and policy. Regardless whether the accused is, or is not, a patient of the forensic clinician, the evaluation and report must be done in a neutral manner without preconceived expectations and biases that could disqualified evaluation and reporting (Zepinic, 2017). However, the dissimulation and malingering the assessor must consider through record review, testing, interviewing, and cross-checking collateral information. Dissociative state of the accused is legally relevant because of the equating of memory loss with lack of intent and involuntariness of behaviour, when appropriate (Bourget et al., 2017).

Conducting assessment of Complex Trauma Syndrome (complex PTSD) with trauma-induced dissociative symptoms can be challenging in psychiatric evaluation with relatively limited time and direct exposure to the evaluee. Comorbid condition of trauma syndrome's dissociation requires the assessment of person's personality functioning and may lead to a false diagnosis of a personality disorder with no clear distinction between comorbidity. This often leads that the assessment should be conducted over an extended time to ensure clear clarification of the trauma-caused dissociation (Zepinic, 2021b). Given that maintaining objectivity and credibility are an essential task to the forensic evaluation, the assessor should perform, as much as it needed, integrity checks to ensure that evaluation and conclusive findings are of the highest quality and accuracy. In general, the forensic evaluation must not be routinely maintained a log of previous cases-every case must be seen as an individual case.

Complex Trauma Syndrome (complex PTSD) may result in individual's gross 
impairment in reality testing, especially when disorder leads trauma victim is reliving a traumatic event(s) or otherwise perceives the surrounding environment to be substantially different (and often more threatening) from that which actually exists (Zepinic, 2017). In clinical practice, this gross altered personality is often found among combat-related trauma syndrome, specifically the relations of the dissociative reactions to criminal behaviour when a war-veteran enters a survival mode brought on by an environment stimulus reminiscent of the combat trauma.

Establishing a causal connection between trauma syndrome's symptoms and the criminal act can be difficult, especially pursuant to the M Naughten test's requirement, and should be taken into account only when dissociative flashbacks led to an unpremeditated criminal act (Frierson, 2013). Frierson (2013) reported an active-duty US soldier who was not found guilty for a murder following him suffered severe stress syndrome:

The soldier had been arrested for six charges of the assault and battery with an intent to kill, discharging a firearm into a dwelling, and possession of a weapon during the violence. While visiting his relatives away from his military basis, he woke up in the early morning and informed his relatives that someone was shooting at him. He grabbed his rifle, drove his truck to another residency a short distance from his relative's house, banged on the front door of a residency demanding entry, and, as nobody opened the door, he began kicking the door. He then fired four shots into the door jam.

The people inside the residency called the police who, on their arrival, found a male lying on the ground in front of the parked vehicle with a rifle on the ground next to him. The soldier began to crawl around in front drive side vehicle and did not respond on the police order to come out with his hands up. The residents did not know the arrested nor had any previous contact with him. The offender also did not know the residents and was totally amnestic about his offence.

The arrested did not have any criminal record, a history of alcohol or drugs abuse, prior psychiatric treatment nor history of the mental illness, and reportedly had no history of the behavioural problems. As a member of the US Army's infantry division, he served in Iraq on two occasions. He never had any injury in combat operation but witnessed a fatal injury to a fellow soldier in a tank accident during his first one-year deployment. According to the military record, in his second deployment to Iraq, he was involved in a door-to-door operation in Fallujah that were designed to find and capture insurgents.

When arrested, the ex-soldier reported the onset of combat nightmares during his second deployment to Iraq which worsened after he left Iraq. One of his recurrent nightmares involved him being under fire by the enemies and discovering that he did not have his weapon. He described feelings of the detachment and estrangement from the others and reported ability to have lov- 
ing feelings for others. He described hypervigilance and reported several incidents as aftermaths of experiencing an exaggerated startle response. According to the police officer while being arrested the ex-solder questioned: "Why are you arresting me from doing my job?". The police officer also reported that arrested did not appear to be in his mind-at time he appeared and behaved like he was in Iraq.

The forensic expert reported that the accused's action was consistent with the PTSD-related dissociative flashback. Because the defendant's behaviour during offence was consistent with both to his military training and his behaviour in the combat, the expert stated that the defendant most likely did not appreciate the nature and quality of his actions or the wrongfulness of his actions (Frierson, 2013).

The above cited case illustrates the "necessity of self-defence" of an individual who suffered Complex Trauma Syndrome (complex PTSD) with dissociative flashback which, from the legal point of view, caused diminished responsibility or insanity. In most countries, the diminished responsibility is recognised for the acquittal of murder or manslaughter (Herring, 2014). The diminished responsibility must arouse from a recognisable medical condition which causes substantial abnormality of mental functioning-impaired inability to understand the nature of doing, absence of rational judgment, and one's inability to self-control of the inner conflict drives.

If the accused's crime was one of violence and he believed that he is there-and-then in the traumatic event which was life threatening, it is reasonable that, due to dissociation, he did not know his actions were wrong as he believed that he is defending his or others life. During such dissociative state, these individuals believe they are in another environment or setting and grossly misconstrue what is occurring (Zepinic, 2017). These trauma syndrome sufferers are neither cognizant of the character of their action nor need for them, and they do not know the nature and quality of the wrongfulness of their action. In Clark case, the court recognised that the individual diagnosed with PTSD experiencing a dissociative state is incapable of knowing the nature and quality of the action or for knowing right from wrong. In many court cases, it was recognised that person driven by dissociated state of mind with suffered loss of control over the inner conflict drives is unable to restrain, nor knowing that his behaviour is wrong.

For the medical (but also the legal) point of view, it is important to note that severe stress-related disorder is primarily a deregulation of the fear system as the fear is a necessary emotion at the time of alleged "danger", and it is followed by a stress response-i.e., fighting, freezing, or fleeing (Zepinic, 2019). The survival due to the "danger" depends on appraisal threats in order to activate initial survival skills (Zepinic, 2015b). The spectrum of one's personality psychopathology and distorted psychic equilibrium caused by severe trauma experience has sig-

${ }^{7}$ Clarck v Arizona, 548 U.S. 735 [2006]. 
nificant outcomes upon the trauma-victim's post-trauma emotion, cognition, perceptions, relationships, and behaviour.

One of our patients with a history of brutal and repeated rape reported:

"Sometimes I have what I think are feelings and thoughts of unreality. I feel strange at times as though everything were not real, even when I am talking to you doc it sounds strange to me and I ask myself if this really me talking and what am I talking about? Sometimes when I see a reflection of myself in a mirror, I got a peculiar sensation. I feel that I am looking at a stranger and I ask myself. Who am I? This always happens when I am distressed with something. I actually sometimes forget what my name is and this happened several times and it makes me feel like I have a twisted mind".

Thus, the trauma-victim's personal encounter, facing with "severe threat or death", confronts person with an alleged danger as a real danger which evokes responses of the inescapable catastrophe. Such response may occur in various forms and degrees of the self-dissolution, delusions, hallucinations, fragmentation, disintegration, and destructiveness (Zepinic, 2019). Severely traumatised person is exposed to "real threat" and remains mobilised for the survival facing inescapable terror without possibility to focus on anything else but on "now moment" as it was during traumatic experience. During this period of dissociative flashbacks, the trauma victims are run by the inner conflict drives-their action is out of control, and it is unconscious (Zepinic, 2017).

Most of the expert's testimony is to evaluate the reasonableness of the person (accused) who perceives a danger having a reasonable perception of it. If the standard is an objective one, then it is more difficult to meet, as the average person under the law should not have a history of abuse, or personality affected by severe trauma experience. The testimony is merely to explain the typical way of perceived "danger" as a reminder of the original trauma rather than the specifics of the particular accused's state of mind. The accused's thinking, feelings, and behaviour should be evaluated in the context of the trauma-induced dissociation which specifically affected psychic equilibrium leading to the delict-the reality or reasonableness of the imminent danger experienced by a sufferer of the trauma syndrome.

\section{Conclusion}

The analysis in this article has served to illustrate complexity for both the law and the medicine to foster court proceedings against the accused who suffered Complex Trauma Syndrome (complex PTSD) with trauma-related dissociation. Damage to the psyche by trauma has throughout the history provoked apprehension, a sense of uncertainty, and ignorance, as these injuries cannot be seen by the naked eye. However, it does not mean that psychiatric injury is any "less real" than physical injury which involve broken bones, the spilling of blood, the scarring of tissues or "physical" pain. In fact, the aftermaths of severe trauma are 
very serious, more deserving of the law's attention than some of a physical nature (Zepinic, 2015a). In McDermott case ${ }^{8}$, Southin J delivered:

"What is logical difference between a scar on the flash and a scar of the mind? If a scar on the flash is compensable although it causes no pecuniary loss, why should a scar on the mind be any less compensable?".

It is even more needed to recognise and quantify injury on the psyche when the sufferer is a subject of criminal proceeding due to his/her wrongdoing. In many countries, jurisdictions provide that injury to the mind is compensable if it is directly attributable to a criminal offence (i.e., rape, child abuse, battered women syndrome, POW). However, in practice the courts very rare compensate trauma victims who suffered trauma-related disorders although, in many cases, severe trauma experience had caused a long-term disturbed psychic equilibrium of the victim. It is beyond the scope of this article to examine these provisions in more details. However, it is worthy to note that in a number of cases of the trauma victims who suffered recognisable psychiatric damages the courts have had recourse to common law principle to determining entitlement.

On the other hand, it is distressing that recognised psychiatric damages are mostly present in courtroom when the sufferer committed crime associated to the stress-related and other mental health disorders (Zepinic, 2017). Dissociative experiences (flashbacks) often occur in reaction to reminders of them and manifest as a disruption in perception of time, physical sensations, memory, sense of self and personal identity, and/or sense of (un)reality. The trauma-induced dissociation occurs when the aspects or discrete components of trauma experience fail to integrate, thereby remaining cut off or inaccessible from each other (Zepinic, 2018) (Zepinic, 2019).

There has been an increased interest in the relationship between PTSD and violence, in particular combat-related or battered women and criminal responsibility determinations, and in factors (i.e., dissociation) that mediate their linkage. The society at large and the criminal justice systems have recognised, belatedly, that a large number of ex-combatant or victims of prolonged and repeated abuse are suffering adverse psychological reactions as an aftermath of their trauma experience. Nevertheless, the Complex Trauma Syndrome (complex PTSD) diagnostic criteria are sufficiently well defined to enable courts to proper understand this mental disorder and its offered basis for defences (in particular in case of battered woman, child abuse, rape), including self-defence, unconsciousness, and diminished capacity.

Trauma-induced dissociation for serious offences (murder, violence, abuse) may lead to a legal repercussion, because of its relevance to the legal constructs for person's responsibility to wrongdoing. For example, dissociative amnesia could render a defendant incompetent and irresponsible for the action because of memory loss for the event and prevent the accused from having a reasonable degree of rational understanding and restrict his ability to assist the attorney in ${ }^{8}$ McDermott v Ramadanovic Estate [1988] 27 BCLR (2 $\left.{ }^{\text {nd }}\right) 45$. 
the preparation of defence (Bourget et al., 2017). As it was described above, the Complex Trauma Syndrome (complex PTSD) with dissociation (i.e., severe rape, child abuse, combat trauma, battered women) is a severe disorder recognised by the courts and meets the usual standard of admissibility for mental health expert's testimony.

The complexity in forensic psychiatric testimony often lies in the difficulty of correlating clinical fundings within the current diagnostic criteria (either the DSM-5 or the ICD-11) and criminal law requirements. Vast majority of the courts focus on statutory requirements of actus reus and less paying attention to means rea. It means, the court is facing its attention on action (delict) not on the person who did act, making findings of the accused's dissociative experiences (i.e., flashback) legally irrelevant. However, the complex trauma is analogous to a high-velocity bullet piercing through the body, tearing apart internal organs critical to survival. Similarly, whereas the brain and heart are critical organs of the body, the self and ego are the core psychic organs for psychological functioning. Without meaningful ways to understand traumatic damage to the self by the complex trauma, it would be like trying to understand degenerative neurological disorders without proper understanding how the brain functions (Zepinic, 2016).

On the other hand, the expert in mental health who provides coherent assessment and report based on clinical knowledge may be in position that his findings are inadmissible, legally unquantifiable and unfocused in the required law's conception (Zepinic, 2017) (Zepinic, 2021a). Our review of the current status of the Complex Trauma Syndrome (complex PTSD) with the trauma-related dissociation in the courtrooms highlights notable advances since the DSM-5 and the ICD-11 manuals were published. This should significantly reduce the gaps in a number of points that bear important implication for both the medicine and the law for the severe trauma sufferers (i.e., battered women, child abuse, rape, victims of terrorism, combat-related stress disorder).

As dissociation represents a disruption in the normally integrated memory and consciousness, it is not uncommon feature of one's crime, violence, or any other types of wrongdoing. To what extent dissociation contributes to the criminal act it is real task for the forensic expert to present before the court. Thorough and thoughtful forensic assessment requires clinical skill about the impact of trauma syndrome with dissociation upon one's personality, memory, cognition, and affects, and circumstances surrounding the offence or wrongdoing. In many court cases it is common that trauma syndrome is accompanied by person's abuse of illicit drugs or alcohol which may even make clinical features worse than the trauma experience itself alone. Nevertheless, the Complex Trauma Syndrome (complex PTSD) diagnostic criteria (either in the DSM-5 or the ICD-11) are sufficiently well defined to enable courts to proper understand this disorder when they dealing with. 


\section{Conflicts of Interest}

The author declares no conflicts of interest regarding the publication of this paper.

\section{References}

American Psychiatric Association (2013). Diagnostic and Statistical Manual of Mental Disorders (DSM-5). Author. https://doi.org/10.1176/appi.books.9780890425596

Bourget, D., Gagne, P., \& Wood, S. F. (2017). Dissociation: Defining the Concept in Criminal Forensic Psychiatry. Journal of the American Academy of Psychiatry and the Law, 45, 147-160.

Brewin, C. R., Cloitre, M. H., Shelvin, M., Maercker, A., Bryant, R. A. et al. (2017). A Review of Current Evidence Regarding the ICD-11 Proposals for Diagnosing PTSD and Complex PTSD. Clinical Psychology Review, 58, 1-15. https://doi.org/10.1016/j.cpr.2017.09.001

Briere, J., Scott, C., \& Weathers, F. (2005). Peritraumatic and Persistent Dissociation in the Presumed Aetiology of PTSD. American Journal of Psychiatry, 162, 2295-2301. https://doi.org/10.1176/appi.ajp.162.12.2295

Cloitre, M., Hyland, P., Bisso, J. I., Brewin, C. R. et al. (2019). ICD-11 PTSD and Complex PTSD in the United States: A Population-Based Study. Journal of Traumatic Stress, 32, 833-842. https://doi.org/10.1002/jts.22454

Courtois, A. C., \& Ford, J. D. (2009). Treating Complex Traumatic Stress Disorder. The Guilford Press.

Freud, S., \& Breuer, J. (1893). On the Physical Mechanisms of Hysterical Phenomena. In S. Freud (Ed.), Collected Papers (Vol. 2, pp. 225-305). International Psychoanalytic Press.

Frierson, R. L. (2013). Combat-Related Posttraumatic Stress Disorder in Criminal Responsibility Determinations in the Post-Iraq Era: A Review and Case Report. Journal of the American Academy of Psychiatry and the Law, 41, 79-84.

Frost, R., Louison, M. V., Karatzias, T., Hyland, P., \& Shevlin, M. (2019). The Distribution of Psychosis, ICD-11 PTSD and Complex PTSD Symptoms among a Trauma-Exposed UK General Population Sample. Psychosis, 1, 1-12. https://doi.org/10.1080/17522439.2019.1626472

Gilbar, O. (2019). Examining the Boundaries between ICD-11 PTSD/CPTSD and Depression and Anxiety Symptoms; a Network Analysis Perspective. Journal of Affective Disorders, 262, 429-439. https://doi.org/10.1016/j.jad.2019.11.060

Harvey, A. G., \& Bryant, R. A. (2002). Acute Stress Disorder: A Synthesis and Critique. Psychological Bulletin, 128, 886-902. https://doi.org/10.1037/0033-2909.128.6.886

Herman, J. (1992). Trauma and Recovery. Basic Books.

Herring, J. (2014). Medical Law and Ethics (5th ed.). Oxford University Press. https://doi.org/10.1093/he/9780198702269.001.0001

Holmes, E. A., Brown, R. J., Mansell, W., Fearon, R. P., Hunter, E. C. et al. (2005). Are There Two Qualitatively Distinct Forms of Dissociation? A Review and Some Clinical Implications. Clinical Psychology Review, 25, 1-23. https://doi.org/10.1016/j.cpr.2004.08.006

Hyland, P., Karatzias, T., Shevlin, M., \& Cloitre, M. (2019). Examining the Discriminant Validity of Complex Post-Traumatic Stress Disorder and Borderline Personality Disorder Symptoms: Results from a United Kingdom Population Sample. Journal of 
Traumatic Stress, 1, 1-9. https://doi.org/10.1002/jts.22444

Hyland, P., Shevlin, M., Brewin, C. R., Cloitre, M. et al. (2017). Validation of Post-Traumatic Stress Disorder (PTSD) and Complex PTSD Using International Trauma Questionnaire. Acta Psychiatrica Scandinavica, 136, 313-322. https://doi.org/10.1111/acps.12771

Janet, P. (1907). The Major Symptoms of Hysteria. Macmillan. https://doi.org/10.1037/10008-000

Janet, P. (1925). Psychological Healing. Allen \& Unwin.

Lechner-Meichsner, F., \& Steil, R. (2021). A Clinical Rating to Diagnose CPTSD According to ICD-11 and to Evaluate PTSD Symptom Severity: Complex PTSD Item Set Additional to the CAPS (COPISAC). European Journal of Psychotraumatology, 12, Article ID: 1891726. https://doi.org/10.1080/20008198.2021.1891726

Loveless, J. (2012). Criminal Law (3rd ed.). Oxford University Press.

Meares, R. (2012). A Dissociation Model of Borderline Personality Disorder. W.W. Norton.

Mullany, N. J., \& Handford, P. R. (1993). Tort Liability for Psychiatric Damage. Sweet \& Maxwell.

Putnam, F. W. (1989). Diagnosis and Treatment of Multiple Personality Disorder. The Guilford Press.

Simon, R. I., \& Gold, L. H. (2004). Textbook of Forensic Psychiatry. American Psychiatric Publishing.

Spiegel, D., \& Cardena, E. (1991). Disintegrated Experience: The Dissociative Disorders Revisited. Journal of Abnormal Psychology, 100, 366-378. https://doi.org/10.1037/0021-843X.100.3.366

Stein, D. J., Koenen, K. C., Friedman, M. J. et al. (2013). Dissociation in Posttraumatic Stress Disorder: Evidence from the World Mental Health Surveys. Biological Psychiatry, 73, 302-313.

Van der Hart, O., Nijenhuis, E. R. S., \& Steele, K. (2006). The Haunted Self. W.W. Norton \& Company.

van der Kolk, B. A., MacFairlane, A., \& Weiseath, L. (1986). Traumatic Stress. The Guilford Press.

Van der Velden, P. G., Kleber, R. J., Christiansen, B., Gersons, B. P. R. et al. (2006). The Independent Predictive Value of Peritraumatic Dissociation for Postdisaster Intrusions, Avoidance Reactions, and PTSD Symptoms Severity: A 4-Year Protective Study. Journal of Traumatic Stress, 19, 493-506. https://doi.org/10.1002/jts.20140

Waelde, L. C., Silvern, L., \& Fairbank, J. A. (2005). A Taxometric Investigation of Dissociation in Vietnam Veterans. Journal of Traumatic Stress, 18, 359-369. https://doi.org/10.1002/jts.20034

Wang, L., Zhang, Y., Wang, W., Shi, Z., Xin, Y. et al. (2009). Symptoms of Posttraumatic Stress Disorder among Adult Survivors Three Months after the Sichuan Earthquake in China. Journal of Traumatic Stress, 5, 444-450. https://doi.org/10.1002/jts.20439

Werner, K. B., \& Griffin, M. G. (2012). Peritraumatic and Persistent Dissociation as Predictors of PTSD Symptoms in Female Cohort. Journal of Traumatic Stress, 25, 401-407. https://doi.org/10.1002/jts.21725

World Health Organisation (2018). International Statistical Classification of Disease and Related Health Problems (ICD-11). Author.

Zepinic, V. (2015a). Fear of the "Floodgate of Liability" and Acknowledgment of the Recognisable Psychiatric Damage into English Law of Tort. Canadian Social Science, 
$11,1-14$

Zepinic, V. (2015b). Persistence of the "Survival Skills" as a Risk Factor for Suicide in Severely Traumatised Individuals. Journal of Emergency Mental Health and Human Resilience, 2, 552-558. https://doi.org/10.4172/1522-4821.1000214

Zepinic, V. (2016). Disintegration of the Self-Structure Caused by Severe Trauma. Psychology and Behaviour Science, 4, 83-92. https://doi.org/10.11648/j.pbs.20160504.12

Zepinic, V. (2017). Posttraumatic Stress Disorder in Courtroom: Insanity Defence. American Journal of Applied Psychology, 6, 22-30. https://doi.org/10.11648/j.ajap.20170602.12

Zepinic, V. (2018). Four-Phased Dynamic Therapy Model in Treating Trauma-Induced Dissociation. Psychology, 9, 1979-2010. https://doi.org/10.4236/psych.2018.98114

Zepinic, V. (2019). The Self and Complex Trauma (2nd ed.). Austin Macauley Publishers.

Zepinic, V. (2021a). Battered Women Syndrome: A Headache for Medicine and Law. Psychology, 12, 843-871. https://doi.org/10.4236/psych.2021.126052

Zepinic, V. (2021b). Complex Trauma Syndrome. Austin Macauley Publishing.

Zepinic, V. (2021c). COVID-19: An Urgency to Address Mental Health Consequences. Psychology, 12, 735-748. https://doi.org/10.4236/psych.2021.125045 